\title{
EL SUJETO EN LA CINTA DE MOEBIUS: IDAS Y VENIDAS NARRATIVAS EN LA CASA DE LOS CONEJOS DE LAURA ALCOBA
}

\author{
The subject in the Moebius strip: narrative comings and goings in \\ La casa de los conejos by Laura Alcoba
}

Jorge Omar Aloy*

\begin{abstract}
RESUMEN
Si consideramos que existe una literatura de la evocación, por ende existe un sujeto que evoca, cuya entidad se halla en el orden de lo empírico. Este sujeto es el que hace posible la narratividad de un texto y crea, entre otros elementos, la voz que asume el control de lo representado. Esta voz, ordenadora del discurso, se encuentra en el terreno de la técnica y presenta ciertas complejidades a la hora de relacionarla con un sujeto humano atravesado por alguna experiencia traumática. En el presente trabajo vamos a analizar el lugar que ocupan las voces narrativas en La casa de los conejos de Laura Alcoba, en donde un solo yo se expande y se enmascara a través de los artificios literarios.

Palabras clave: evocar, narradora, lectura, sujeto, ethos.
\end{abstract}

\begin{abstract}
If we consider that there is an evocating literature, therefore there is a subject who evokes, whose entity is in the order of the empirical. It is the subject who makes possible the narrativity of a text and creates, among other things, the voice that assumes the control of the represented. This voice, that orders the speech, is located in the field of the technical and shows some complexities when relating to the human subject, who had gone through some traumatic experience. In this work, we are going to analyze the place occupied by the narrative voices in La casa de los conejos by Laura Alcoba, where a single self expands and masks through the literary artifices.
\end{abstract}

Key Words: evoke, narrator, reading, subject, ethos.

Universidad Nacional de Lomas de Zamora. Docente y Licenciado en Letras. Argentina.

Correo electrónico: jorgealoy@yahoo.com.ar

Recepción: 11/2/17. Aceptación: 19/4/17. 


\section{El ensanchamiento de la lectura}

La coincidencia biográfica entre escritor, narrador y personaje en la literatura que evoca hechos traumáticos, más allá de generar cierta unidad enunciativa concibe en el plano discursivo una suerte de puesta en abismo. En el momento del encuentro (o alejamiento) de esas tres figuras se produce un conflicto, derivado de la interacción que originan, en donde el enfoque de la lectura se ensancha. En consecuencia, el texto alcanza nuevas significaciones.

Mientras el sujeto que evoca sugiere que es él quien narra la obra, podemos creer que, efectivamente es él, pero atravesado por los juegos narrativos que ofrecen estrategias y tácticas de enmascaramiento o de expansión, o es él atravesado por los prejuicios que la distancia del tiempo construyó en su propia subjetividad. En este sentido, Tzvetan Todorov afirma que "El yo presente es una escena en la cual intervienen como personajes activos un yo arcaico, apenas consciente, formado en la primera infancia, y un yo reflexivo, imagen de la imagen que los demás tienen de nosotros [...]" (2000: 26). Además, el sujeto que evoca es el que se presenta a sí mismo como personaje. Es un personaje que remite al pasado del escritor, terciado por recuerdos y olvidos reconstruidos una y otra vez. Simultáneamente, es una representación mediada por los deseos, en donde el que evoca intenta verse a sí mismo actuando de una manera determinada en un pasado traumático.

En La casa de los conejos, Laura Alcoba rememora, a través de su experiencia infantil, algunos sucesos familiares previos a la dictadura cívico-militar argentina. El año 1975 fue la antesala de la represión, el asesinato y la desaparición de personas, hechos que caracterizaron a la dictadura inmediatamente posterior. En ese contexto, Alcoba presenta una historia, la suya propia, inscripta en los días aciagos del país, desde el momento en que su padre fue detenido, cuando su madre, junto a compañeros de militancia, debió pasar a la clandestinidad. Estos acontecimientos están ligados a la memoria de la escritora e infunden en ella el leitmotiv de la narración. Por lo tanto, encuentra aquí gran asidero la afirmación de Wladimir Krysinski cuando dice que "Como actividad cultural, la literatura tiene su origen en el cuerpo del sujeto. La reflexión y la sublimación se engendran en y por la relación dinámica entre el sujeto y el mundo" (2009: 274).

En el sentido de lo que se ha venido desarrollando, se puede plantear que la escritora es la primera referencia en el juego de la puesta en abismo. En el otro extremo se encuentra Laura, el personaje, la niña que pierde toda forma literal de la vida, ya que comienza a vivir rodeada de símbolos y fachadas que niegan lo que representan. En esta madeja ya no se problematiza solo lo que se anhela contar, sino que pasa a un primer plano el modo en que se pretende hacerlo. A instancia de estas necesidades, el texto plantea una alerta sobre la multiplicidad de signos que configura al sujeto. En otras palabras, transforma la negación del estatuto, estable del sujeto en la única posibilidad de concreción de la escritura. Tal concreción, como si fuera un efecto más del desdoblamiento del sujeto, parece ser posible solo con la renuncia a la lengua materna y a la eventual adopción de la lengua francesa que realiza Alcoba. Adriana Bocchino es tajante en este sentido cuando expresa la siguiente reflexión: "Sospecho una renuncia a la lengua para salvar a la madre y al padre. Sospecho un ir despacio, muy despacio, en el intento de reconstrucción de una vida recién después de treinta años" (2015: 75). La narración busca separarse del recuerdo, y para ello se separa de la lengua del recuerdo. Quizá sea un modo de alejarse, de tomar distancia temporal, para conseguir que se haga factible el recurso que habilite el discurso ficcional.

Finalmente, la narradora es la encargada de poner en tensión los sucesos fácticos con la técnica narrativa. Ella ocupa, por supuesto, un lugar decisivo en la obra, pero no debemos perder de vista que su configuración es, también, meramente literaria. Los juegos narrativos, presentados como idas y venidas, como mezcla de voces, son los que dan fuerza a La casa de los conejos en toda su significación. Estos juegos son los que producen la puesta en abismo y el consiguiente ensanchamiento de la lectura. 


\section{Un inicio estratégico}

La casa de los conejos tiene un comienzo que pretende encontrar una justificación al acto conjunto de la escritura y la memoria. “Te preguntarás, Diana, por qué dejé pasar tanto tiempo sin contar esta historia. Me había prometido hacerlo un día, y más de una vez terminé diciéndome que aún no era el momento" (Alcoba, 2013: 11). Es una voz situada fuera de la evocación que persistirá a lo largo de la obra, pero que, simultáneamente, plantea una problemática en cuanto a la definición del marco narrativo. Es una confesión que se presenta sin ninguna identificación, sin título ni numeración de capítulo, destinada a Diana, su narrataria, y por extensión a los lectores. Bruno Ragazzi analiza las representaciones discursivas en torno a las maneras de ver el pasado y considera que en el paratexto que denomina prólogo-carta se halla un indicador que define al subgénero de la novela-testimonio: “(...) por ejemplo, el prólogo-carta a Diana Teruggi al principio de la misma (la obra), en el que Laura resuelve los motivos de su búsqueda por los intrincados caminos de la memoria" (2013: 128). Como vemos, Ragazzi llama "prólogo-carta" a ese texto que problematiza el modo de la lectura. ¿Qué lugar ocupa en la historia? Álvaro Pineda Botero sostiene que "Si queremos establecer el punto en donde se inicia la novela, deberíamos estar atentos al momento en que el discurso del autor pasa de natural a ficticio" (2013: 284). El apartado que mencionábamos cumple una función lingüística que supera lo meramente formal de la presentación del texto ficcional y roza cierto encuadramiento con el discurso natural. Para discernir sobre las implicancias que pueda tener sobre la totalidad del texto, creemos que debemos considerar que Laura Alcoba necesita legitimarse ante los lectores y, para ello, debe construir su ethos, al igual que en un discurso retórico. Debe cimentarse a sí misma como una figura que inspire confianza en el lector. Por lo tanto, la escritora no debe hablar de sí, sino que debe mostrarse. El especialista en análisis del discurso, Dominique Maingueneau aleja toda extrañeza que puede generar la utilización de esta estrategia argumentativa en un texto de ficción y sostiene que "Todo discurso, oral o escrito, supone un ethos: implica cierta representación del cuerpo de su garante, del enunciador que asume su responsabilidad" (2008: 48) (Las cursivas son de Maingueneau). El garante es el que a través del modo de decir pone en acción el enunciado y da forma al mundo creado. Si bien, este mundo puede ser conocido por el lector, siempre cabe la posibilidad de que existan puntos que deban reafirmarse, entre ellos la anulación de las ambigüedades a la hora de la conformación del contexto histórico. Alcoba lo confirma cuando dice "Voy a evocar al fin toda aquella locura argentina, todos aquellos seres arrebatados por la violencia. Me he decidido, porque muy a menudo pienso en los muertos, pero también porque ahora sé que no hay que olvidarse de los vivos" (2013: 12).

La conformación del ethos persigue una estrategia de elaboración que, en el caso que nos ocupa, combina el contexto histórico, la justificación de la escritura y el lugar particular de la protagonista en la historia general. Esta combinación, producida al calor de una estrategia discursiva, generará un efecto en los lectores: a través de ella podremos confiar o no en la voz venidera. La introducción (o prólogo-carta, alguna denominación debemos darle), además, establece un puente discursivo con el resto del texto evocativo a través de la confesión. La última de las confesiones dice: "[...] Si al fin hago este esfuerzo de memoria para hablar de la Argentina de los Montoneros, de la dictadura y del terror, desde la altura de la niña que fui, no es tanto por recordar como por ver si consigo, al cabo, de una vez, olvidar un poco" (Alcoba, 2013: 12).

El ethos se erige buscando una relación empática con el lector y aquí, Alcoba plantea su trauma y la necesidad de olvidarlo. Nadie puede exigirle lo contrario. El olvido, en las presentes circunstancias, se presenta paradójicamente como el efecto que podría causar la verbalización del trauma. Dicho de otro modo, la voz introductoria espera a través de su narración dar a luz a un pasado negado para conseguir, en consecuencia, el olvido del 
trauma que la persigue. El olvido se presenta, entonces, como una necesidad pero también como un derecho. En esta línea de pensamiento, Todorov asegura que:

\begin{abstract}
La recuperación del pasado es indispensable; lo cual no significa que el pasado deba regir el presente, sino que, al contrario, éste hará del pasado el uso que prefiera. Sería de una ilimitada crueldad recordar continuamente a alguien los sucesos más dolorosos de su vida; también existe el derecho al olvido (2000: 25 ).
\end{abstract}

Una vez finalizado este prolegómeno estamos preparados para evitar cualquier lectura ingenua de La casa de los conejos. Lo que sigue está dividido en capítulos numerados. Por lo tanto, la voz de esta introducción se diluye para dar paso a otras, pero deja algunas preguntas: ¿Qué lazos pretende establecer con la narradora que a continuación se presenta en el conjunto de los capítulos? ¿Puede algún editor futuro eliminarla del texto según la conveniencia literaria de ese momento histórico? ¿Es realmente Laura Alcoba la que habla o es una máscara ficcional más? ¿Volverá posteriormente para retomar la posta discursiva en la novela? Roland Barthes dice que "La escritura es la destrucción de toda voz, de todo origen" (1987: 65). No hay dudas de que el sentido último nos está vedado, ya que la escritura tampoco tiene un sentido último y definitivo. En todo caso, sí podemos inferir que esta voz cumple varios papeles, y que su estrategia mayor es la conformación del ethos para alcanzar la legitimación de Laura Alcoba ante sus lectores.

\section{Narradoras}

Es justo hablar en plural para referirnos a la voz narrativa de La casa de los conejos. La novela se inicia con la voz de Laura en el momento evocado, en 1975. La niña de siete años habla en el mismo instante en el que suceden los acontecimientos. Este recurso se denomina presente actual y permite, en la evocación, dejar la sensación de que el recuerdo es preciso. ¿Qué sentido tendría leer a alguien que evoca si presentara lagunas en el recuerdo? Cuando Paul Ricoeur reflexiona sobre la problemática del olvido en la representación del pasado, refiere que la memoria y el olvido no son separables, que no hay una sin el otro. Siguiendo esta línea, sostiene que " $\mathrm{Si}$ no podemos acordarnos de todo, tampoco podemos contar todo. La idea de relato exhaustivo es una idea performativamente imposible. El relato entraña por necesidad una dimensión selectiva" (1987: 572). Es decir que entran en contacto la memoria y la narración para enfrentar la imposibilidad de poder contarlo todo, ya que si lo que se denomina pasado histórico queda librado solo a la narración que ofrecen los grupos de poder, el olvido sería forzado. "Se utiliza aquí una forma ladina del olvido, que proviene de desposeer a los actores sociales de su poder originario de narrarse a sí mismos" (Ricoeur, 1987: 572). En consecuencia, Laura Alcoba demuestra que existen innumerables modos de contar el pasado y adopta un papel activo en la lucha contra el olvido. Por lo tanto, esa niña que todo recuerda ya no habla solo para Diana y los lectores (como la voz de la introducción) sino que se dirige, también, a aquella tradición de relatos de la dictadura argentina que el tiempo estaba fosilizando y viene a proponer la posibilidad de una lectura polisémica.

Si bien nuestro interés teórico no está puesto en pensar la obra de Alcoba como narración autobiográfica, sino como literatura de evocación, es de destacar la denominación autobiografía oblicua que postula Adriana Imperatore. En la autobiografía tradicional existe un

\footnotetext{
desdoblamiento donde el yo se convierte en objeto de la propia escritura y también se producen discontinuidades y saltos entre los planos supuestamente soldados del yo autor, yo narrador y yo personaje; veamos qué pasa en estas novelas donde el objeto no es únicamente el yo convertido en otro de sí mismo, sino que se narra la historia de los padres y sus compañeros militantes objetivados o subjetivados a través de la mirada del yo; de ahí que podrían pensarse como novelas autobiográficas con cierta oblicuidad, puesto que siempre aparecerá este doble plano tanto en la voz que narra, como en los personajes (Imperatore, 2013: 41).
} 
Ese doble plano se produce en la voz de La casa de los conejos. Luego de la niña, surge una segunda narradora: Laura adulta. Esta voz irrumpe en el texto señalando que habla desde un tiempo otro, cercano al presente del tiempo histórico que comparte con el lector. Esta situación nos revela, entonces, que la voz adulta es la misma que leímos en la introducción, y que la entrega de la palabra a la niña se enmarca en la búsqueda de una perspectiva que muestre naturalmente las vivencias que el tiempo convirtió en trauma. Carolina Grenoville dice, sobre la enunciación de esta novela, que "La narradora se convierte así en un ventrílocuo que se limita a prestar simplemente su voz a la niña creando la apariencia de que es esta última la que habla" (2010: párr. 7). Por lo tanto, la narradora adulta, que asimila en ella a la niña evocadora, viene a intentar poner orden en las cosas que creía naturales o que no entendía del pasado. En el capítulo seis recuerda que de pequeña escuchaba la palabra embute y creía que pertenecía al lenguaje de uso ordinario. El término viene a representar una fachada que no muestra lo que efectivamente es: "Desde el mismo instante en que empecé a hurgar en el pasado [...] fue esa palabra el primer elemento sobre el que me sentí compelida a investigar" (Alcoba, 2013: 47). Mientras que de niña no alcanzaba a comprender que embute pertenecía a una jerga del ámbito revolucionario de los setenta, de adulta se ve impelida a investigar.

Debemos destacar el mérito técnico de la novela en cuanto a que no se vislumbra ninguna transición entre una narradora y otra, como si no hubiera mediado ninguna temporalidad entre ellas. Si bien la aparición de la narradora adulta es una irrupción en el discurso ficcional, la podemos pensar como un llamado de advertencia que alerta sobre lo que estamos leyendo que nos indica que no debemos olvidar que los personajes del texto no son creación de la imaginación, o al menos no lo son desde un punto cero de la imaginación, pues el recuerdo enhebró lazos que forjaron la construcción ficcional. En consecuencia, más allá de poner en cuestión la ficción, propone nuevos pactos de lectura a partir de la ingenuidad que comparten ambas narradoras.

La distinción entre las dos voces que cuentan la historia se diluye con la aparición de una tercera voz. Esta presencia no es ostentosa y se filtra por los intersticios que dejan las dos narradoras que ya mencionamos. Es una voz que ofrece vacilaciones en el ejercicio de la memoria, que alerta sobre el olvido y que se muestra intermitente en el discurso. Una prueba de ello se hace evidente cuando la niña muestra afectación por lo que ocurre en su entorno y cuenta sobre el tipo de vida familiar que desearía tener:

Tengo la impresión de que ella [la madre] no ha comprendido bien. Referirme a una casa de tejas rojas era, apenas, una manera de hablar. Las tejas podrían haber sido rojas o verdes; lo que yo quería era la vida que se lleva ahí dentro. Padres que vuelven del trabajo a cenar, al caer la tarde. (...). Una madre elegante con uñas largas y esmaltadas y zapatos de taco alto. O botas de cuero marrón, y, colgando del brazo, una cartera haciendo juego. (...). En el fondo, no era una cuestión de color, no, ni en el caso de las tejas, las botas o el tapado. Me pregunto cómo hemos podido entendernos tan mal; o si en cambio ella se obliga a creer que mi único sueño, el mío, está hecho de jardín y color rojo.

Por otro lado, era un perro lo que yo más quería.

O un gato. Ya no sé. (Alcoba, 2013: 14)

La aparición de una nueva narradora se produce sigilosamente. La niña siempre habla en el tiempo denominado presente actual, y en el final del segmento que citamos aparece una voz que altera temporalmente el discurso. ¿Quién es la que duda respecto a si lo que quería era un perro o un gato? ¿El "ya no sé” se refiere al tiempo del personaje o al tiempo histórico de una narradora que evoca? Es una voz que ingresa en el discurso discretamente, y de modo indirecto afirma lo que aquella niña pensaba. No es una voz ociosa en el juego narrativo de la novela. Se ubica entre las otras dos voces y regula el modo en que Laura Alcoba construye su ethos. Lo regula porque esta tercera voz no narra el pasado, lee (a la par de nosotros) y lo comenta. Luego, se retira silenciosamente. 


\section{Penúltimas palabras}

Comenzamos este breve estudio señalando la coincidencia biográfica entre la escritora, la narradora y el personaje protagonista. Indicamos, además, que esta coincidencia otorga a $L a$ casa de los conejos una sensación de puesta en abismo que ensancha el sentido de la lectura. Hemos identificado también una serie de complejidades narrativas. Llegados a este punto, consideramos que el sujeto evocador, en este caso Laura Alcoba, descarta el discurso lineal. María Teresa Andruetto afirma que "La literatura 'de memoria', como toda la literatura, necesita construir con las palabras un plus de sentido, una distorsión o un corrimiento de lo conocido o de lo sucedido, una incomodidad radicalizada, que nos saque de toda certeza" (2015: 160). En este sentido, el discurso narrativo puede resultar un artilugio valedero para disimular la experiencia traumática $\mathrm{y}$, de modo simultáneo, cuestionar la unidad del sujeto totalizante. Precisamente, la posibilidad de incluir varias voces en la narración, que puedan ir y venir, otorga un nuevo estatuto a la lectura de los acontecimientos traumáticos de la dictadura cívico-militar argentina. El sujeto se expande en el texto, y la expansión produce nuevas significaciones en la lectura.

Si bien todas las voces que asumen el rol narrativo en La casa de los conejos corresponden biográficamente a Laura Alcoba, cumplen su función interpelando el estatuto estable del sujeto. La pregunta que nos quedaría por hacer es si podemos considerar a Laura Alcoba como un único sujeto presente en el texto ¿Es la misma a los siete años que cuando consiguió producir la novela? El sujeto se disemina en el texto a través de una serie de narradoras y enfrenta la estabilidad que proponía el sujeto cartesiano. La visión de la razón totalizante el cogito que funda la Modernidad- no pudo prever la fragmentación de la subjetividad de estos tiempos. Por ende, tampoco pudo prever las múltiples miradas que permiten que el yo se esparza en sus distintas composiciones textuales, que vaya y venga como en una cinta de Moebius, en un constante movimiento, sin principio ni fin, sin afuera ni adentro.

\section{Bibliografía}

Alcoba, Laura. 2013. La casa de los conejos. Buenos Aires: Edhasa.

Andruetto, María Teresa. 2015. "Literatura y memoria". En: La lectura, otra revolución: 159-175. Buenos Aires: Fondo de Cultura Económica.

Barthes, Roland. 1987. "La muerte del autor". En El susurro del lenguaje. Más allá de la palabra y de la escritura: Barcelona: Ed. Paidós.

Bocchino, Adriana A. 2015. "Manège o La casa de los conejos de Laura Alcoba ¿Tan solo un problema de traducción?". En Castro, Andrea y Forné, Anna (Comps.). De nómades y migrantes. Desplazamientos en la literatura, el cine y el arte hispanoamericanos: 61-79. Rosario: Beatriz Viterbo Editora.

Grenoville, Carolina. 2010. "La memoria de las palabras. El relato de la experiencia en La casa de los conejos de Laura Alcoba". En: Actas del IV Congreso Internacional de Letras Transformaciones Culturales. Buenos Aires: Editorial de la Facultad de Filosofía y Letras de la Universidad de Buenos Aires. En prensa.

Imperatore, Adriana. 2013. "Una autobiografía oblicua: la memoria clandestina en Los pasajeros del Anna C. y La casa de los conejos de Laura Alcoba". En: Les Ateliers du SAL. 3: 34-48. Université Paris Sorbonne. Institut d'Études Ibériques et Latino-américaines. Recuperado de https://lesateliersdusal.com Consulta: 14 de diciembre de 2015.

Krysinski, Wladimir. 2009. "'Subjectum comparationis': Las incidencias del 
sujeto en el discurso". En: Angenot, M., Bessiere, J.; Fokkema, D. y Kushner, E. (Dirs.). Teoría literaria: 270-286. México: Siglo XXI.

Maingueneau, Dominique. 2008. Los términos clave del análisis del discurso. Buenos Aires: Nueva Visión.

Pineda Botero, Álvaro (2013). Teoría de la novela. Amazon.com.
Todorov, Tzvetan. 2000. Los abusos de la memoria. Barcelona: Ed. Paidós.

Ragazzi, Pablo. 2013. "Autoficción y trabajo de memoria en La casa de los conejos de Laura Alcoba". En: Orbis Tertius 19: 126-134. La Plata: UNLP. Recuperado de http://www.orbistertius.unlp.edu.ar/ Consulta: 16 de diciembre de 2015.

Ricoeur, Paul. 1987. "El olvido". En La memoria, la historia, el olvido: 531-581. Buenos Aires: Ed. F.C.E.

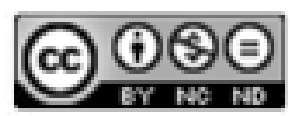

Este obra está bajo una licencia de Creative Commons Reconocimiento-NoComercial-SinObraDerivada 4.0 Internacional. 